\title{
Extraction, Evaluation, and Antioxidant Activity of Total Phenol from Callus of Abutilon indicum (L.) Sweet
}

\author{
Jestin Anula Jomi ${ }^{1}$, Saravanamuthu Abarna ${ }^{1}$, Thiyarajan Sathishkumar ${ }^{1}{ }^{(\mathbb{D}}$, \\ Ramakrishnan Baskar ${ }^{1}$ (D), Peraman Muthukumaran 1,*(D) \\ 1 Department of Biotechnology, Kumaraguru College of Technology, Coimbatore - 641049, TamilNadu, India \\ * Correspondence: muthukumaran.p.bt@kct.ac.in (P.M.);
}

Scopus Author ID 56394355300

Received: 21.04.2021; Revised: 26.06.2021; Accepted: 28.06.2021; Published: 7.09.2021

\begin{abstract}
In this present study, callus induction from the leaves of Abutilon indicum was performed and evaluated antioxidant potential after TLC, PTLC. For induction of callus, Murashige, and Skoog (MS) medium with $2.5 \mathrm{mg} / \mathrm{L}$ concentration of 2, 4 Dichloro phenoxy acetic acid (2,4-D) and for assay, Folin Ciocalteau method practiced for evaluation of total phenol, modified spectrophotometer method used for DPPH assay. Based on total phenolic content, total antioxidant capacity, DPPH, assay, and reducing power assay performed after separation and partial purification of total phenols by Thin-layer chromatography (TLC) and Preparative thin-layer chromatography (PTLC), respectively. For total phenol estimation, hot water extract shows the highest total phenol content $(10.56 \mu \mathrm{g} / \mathrm{ml})$ by comparing another extract; similarly, PTLC fraction of callus extract from Abutilon indicum shows $61 \%$ of inhibition in DPPH at $10 \mu \mathrm{g} / \mathrm{ml}$. From this study, compared to leaf, callus shows a higher concentration of total phenol and shows promising antioxidant activity. So, it gives scope for further exploration and purification and application of total phenol from callus of Abutilon indicum.
\end{abstract}

Keywords: Abutilon indicum; callus; total phenol; antioxidant assay.

(C) 2021 by the authors. This article is an open-access article distributed under the terms and conditions of the Creative Commons Attribution (CC BY) license (https://creativecommons.org/licenses/by/4.0/).

\section{Introduction}

Abutilon indicum (Linn.) sweet is a therapeutic plant, normally known as Thuthi in Tamil /Atibala in Sanskrit. It belongs to the Malvaceae family. It is also called Country Mallow in English and can grow up to 3 feet high [1]. It is an erect, woody, and perennial shrubby plant abundant throughout tropical nations [2]. It is a common roadside weed and is listed among the endangered species of medicinal plants, but it is quite populated in the southern states of Tamil Nadu and Kerala [3]. Customarily, it was accounted for that the plant has therapeutic qualities; for example, leaves are powerful against ulcers and as a fomentation to excruciating pieces of the body[4]. The leaf's decoction is utilized in delicate gums, toothache, and inside for aggravation of bladder. Roots are successful as a demulcent in chest infection, diuretic and urethritis. The bark is utilized as astringent, alexeteric, anthelmintic, febrifuge, and diuretic though seeds are utilized as purgative, expectorant, piles, and so on [5].

All aspects of the plant have therapeutic properties [6]; however, it was found that leaves have more therapeutic properties. In people's medication, A. indicum is utilized in treating fever, lung infection, hack, mumps, deafness, menorrhea, hemorrhoids, pee yield, pneumonic tuberculosis, high fever, diabetes, and ringing in the ears [7,8]. Also, previous reports on leaf separates showed antibacterial, hypoglycemic, larvicidal, carminative, hyper- 
lipidemic, antipyretic, anti-cough, diuretic, blood tonic, diuretic, and anti-inflammatory properties [9]. The leaf juice is utilized for snappy ulcer mending, easing thirst, loose bowels, gonorrhea, bladder irritation, clean wounds, and ulcers, to treat vaginal diseases, as well as is being utilized as a douche [10]. The plant has adhesive tannins, flavonoids, gallic corrosive, sesquiterpenes, aspergines, phenolic mixes, alkaloids, and saponins [11].

The plant has various properties, such as hypoglycemic, hepatoprotective, antimicrobial, anti-inflammatory, male contraceptive, and anti-diarrheal [12,13]. Phytochemicals such as Phenolics have received greater attention as they are identified as biological response modifiers, and they perform functions such as metal chelators and free radical terminators [14]. The active compounds present in the phenolics have the right structural features for free radical scavenging activity, so they are potent antioxidants [15]. A.indicum leaves displayed strong antimicrobial movement against bacterial and parasitic strains test [16]. From the leaf-derived callus of Abutilon indicum the phytochemical analysis of bioactive compounds was carried out [17]. Thin-layer chromatography (TLC) and Preparative thin-layer chromatography (PTLC) analysis of an ethanolic extract of callus revealed the presence of total phenol. The spots that coincide with the standard were marked. Spots of samples were scrapped and pooled together and concentrated for further analysis [18]. FRAP is a method used to measure the total reducing power of the electron donors, and it was performed by a modified method described [19].

In FRAP assay, the antioxidant capacity of compounds is determined by the reducing power of the biological material(antioxidant) on reaction with ferric tripyridyltriazine ( $\mathrm{Fe}^{3+}-$ TPTZ) complex and to produce a blue colored complex of ferrous tripyridyltriazine $\left(\mathrm{Fe}^{2+}\right.$ TPTZ). Using DPPH assay, the free radical scavenging effect was assessed as described. DPPH assay is one of the most sensitive antioxidant testing assays, and it is independent of the substrate polarity [20]. It relies on the measurement of antioxidant ability to scavenge the DPPH radical. It is a stable nitrogen-centered free radical, which is violet in color in ethanol solution. It reacts with suitable reducing agents and loses color depending upon the number of electrons taken up. The potency of the antioxidant compound increases with a rapid decrease in absorbance. Total antioxidant capacity was evaluated by using phosphomolybdenum method [21]. This work aims to identify a better source and estimate the antioxidant activity of total phenolic compounds from induced callus of Abutilon indicum.

\section{Materials and Methods}

\subsection{Plant sample collection and authentication.}

The plant Abutilon indicum was collected from Saravanampatti, Coimbatore - 641035 , Tamil Nadu, India, and the same plant was identified as Abutilon indicum (L.) Sweet Malvaceae. by Botanical Survey of India (BSI), Southern Regional Centre, TNAU Campus, Coimbatore - 641 003. Reference No. BSI/SRC/5/23/2018/Tech / 1168.

\subsection{Induction of callus and preparation of extract.}

The leaf samples of A.indicum were collected from Saravanampatty, Coimbatore. They were washed with normal and distilled water and are surface sterilized using $1 \%$ mercuric chloride. Callus was induced by using MS media with $2 \mathrm{mg}$ 2,4-D. For the preparation of 
extracts, both leaf and callus were taken. Each $1 \mathrm{~g}$ of leaf and callus sample was taken and were crushed by mortar and pestle using hot and cold water and stored for further study.

\subsection{Determination of total phenol.}

The total phenolic assay was determined using the Folin Ciocalteau method with the following procedures [22]. 20 of all four samples, i.e., hot leaf extract, cold leaf extract, hot callus extract, cold callus extract, each is taken in different tubes, and all the tubes are made up to $1 \mathrm{ml}$ with distilled water. To each tube, $0.5 \mathrm{ml}$ of Folin's reagent and $2.5 \mathrm{ml}$ of $20 \%$ sodium carbonate were added. The tubes were then kept in the dark for 40 mins. Then the absorbance value was estimated at $725 \mathrm{~nm}$. The concentration can be determined now using the standard graph of gallic acid.

\subsection{Identification and separation of total phenols by TLC and PTLC.}

The thin-layer chromatography method was followed by [23] with slight modifications. TLC identified flavonoids present in the crude extract performed under the following conditions: adsorbent layer over the glass plate was silica gel 60, the thickness of the layer was about $0.25 \mathrm{~mm}$, size of the layer was about $20 \times 10 \mathrm{~cm}$, and the glass chamber was about $25 \times 25 \times 14 \mathrm{~cm}$, solvent mixture was taken in an appropriate ratio. Similarly, PTLC was also carried out in glass plates where the procedure is similar to TLC, which was explained by [24].

\subsection{Evaluation of the antioxidant potential of total phenol.}

\subsubsection{Total antioxidant capacity assay.}

The total antioxidant capacity assay is based on the principle of reduction of molybdenum (VI) to molybdenum(V) by the extracts and subsequent formations of green phosphate/molybdenum complex at acid $\mathrm{pH} 0.1 \mathrm{ml}$ of the extracts at different concentrations [25].

\subsubsection{DPPH radical scavenging activity assay.}

This method was measured by the modified spectrometer method. The principle of this method is that DPPH radical is scavenged by antioxidants through the donation of protons forming reduced DPPH. The solution loses color depending on the number of electrons taken up. The color changes from purple to yellow after reduction, and the antioxidant activity is determined by the decrease of absorbance at $517 \mathrm{~nm}$ [26].

\subsubsection{Reducing antioxidant power assay.}

The reducing antioxidant power assay method is used to determine the antioxidant property present in the samples, which is based on the principle that when the substance reacts with potassium ferricyanide to form potassium ferrocyanide, which then reacts with ferric chloride to form a ferric ferrous complex that has an absorption maximum at $700 \mathrm{~nm}$ [27].

\subsection{Statistical analysis.}

All the experiments were triplicated, and standard deviations were represented in that all data and experimental results. 


\section{Results and Discussion}

\subsection{Callus induction.}

The explants (leaves) were cultured on the media slants to induce the callus using the formulations mentioned above. Initiation of callus was observed after one week of culture, as shown in Figure 1. Callus was produced from the entire cut end of leaf explants after 2 weeks of culture, which was reported in the article [10].

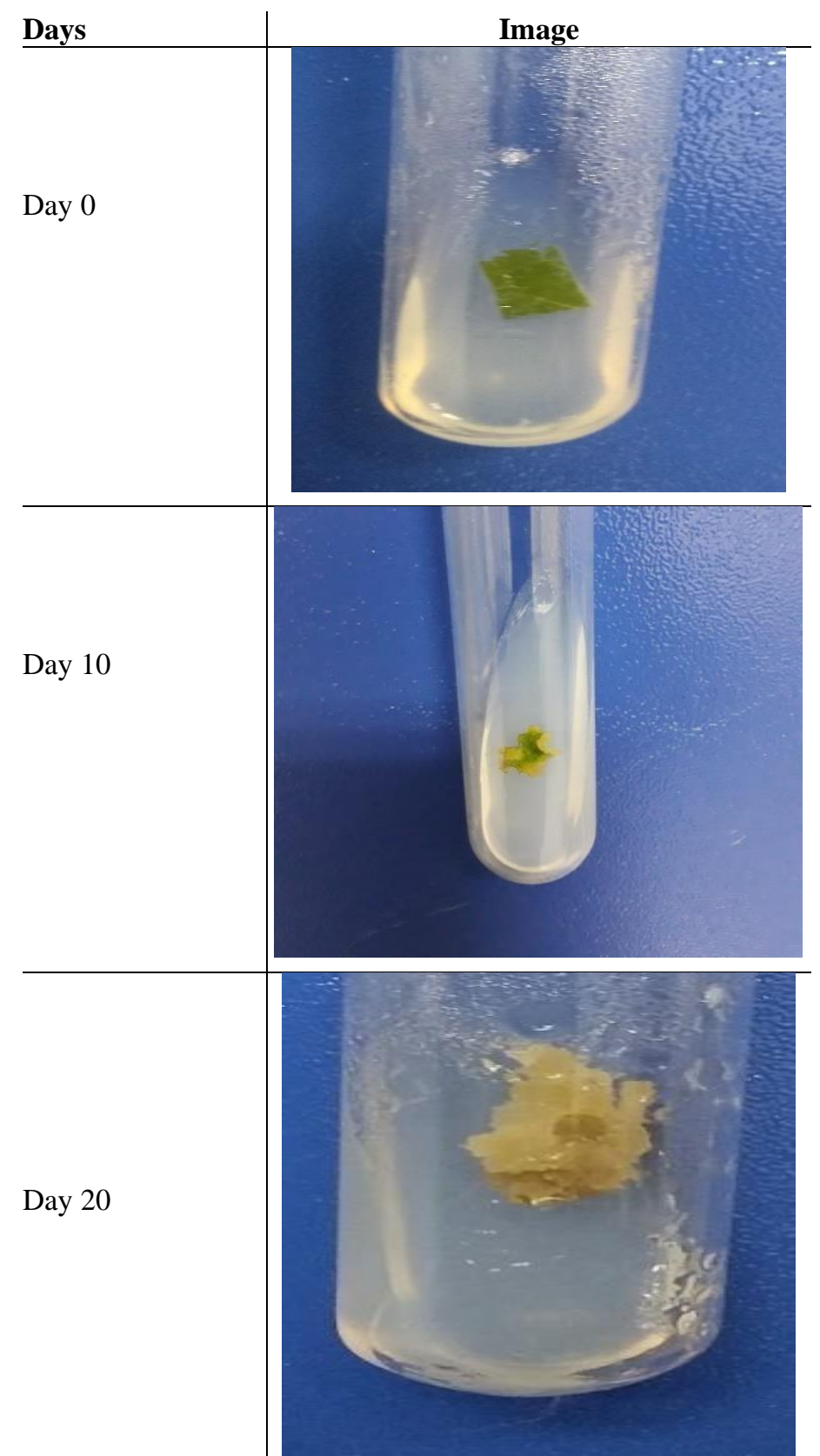

Figure 1. Callus induction from Abutilon indicum leaf explant by using MS media.

\subsection{Estimation of total phenol.}

Figure 2 shows, total phenol content for leaf and leaf derived callus of Abutilon indicum using water as a solvent; phenolic content was measured using gallic acid as the standard graph. It has been reported that phytochemical examination showed that alkaloids, phenolics, carbohydrates, protein, and amino acids were present in the methanolic extract [28]. In the study reported in [10]. Has shown that phytochemical screening of methanolic extract of leaf 
and leaf derived callus revealed that both Abutilon leaves and leaf derived callus possess alkaloids, flavonoids, tannins, and phenolic compounds.

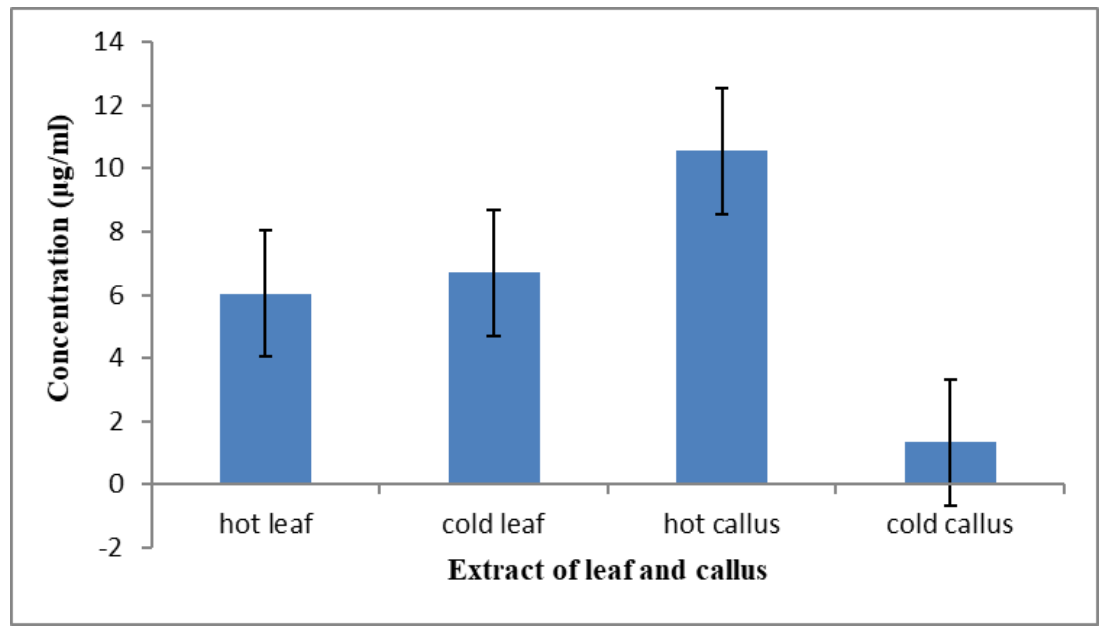

Figure 2. Total phenolic content of leaf and callus extracts.

\subsection{Separation and identification of total phenol from callus extract.}

Figure 3 revealed the presence of total phenol from TLC plate under UV chamber. After confirming total phenol, extracts separated total phenol by using PTLC and bulk extraction of total phenol carried out from the PTLC silica plate. The final fraction from PTLC, was lyophilized and stored for further study.

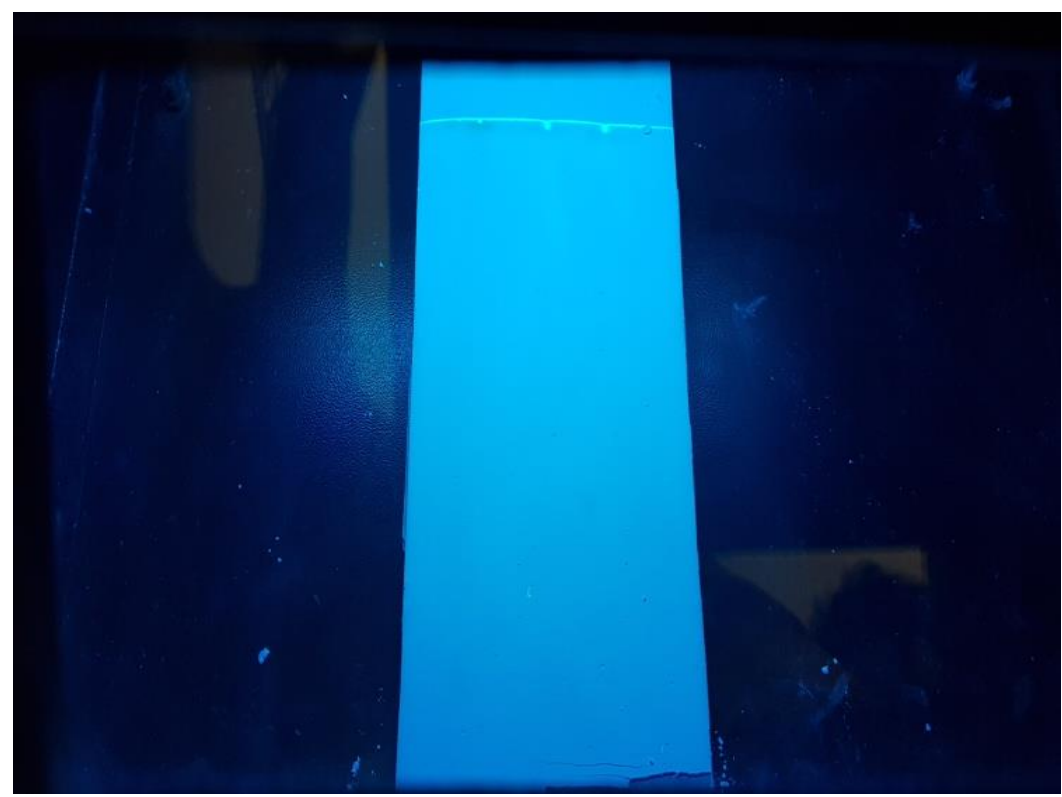

Figure 3. Fluorescent spots of total phenol in TLC under UV illumination.

\subsection{Total antioxidant capacity assay.}

Antioxidants are substances that can prevent or slow damage to the cells caused by free radicals. Total antioxidant capacity is the general antioxidant assay used to determine antioxidants present in the sample extracts. The antioxidant activity was reported for few chemical compounds in the article [29]. Here the sample extracts with varying concentrations were compared to the standard values of ascorbic acid, and it has been found that with increasing concentrations, the equivalence of ascorbic acid also increased, as shown in Figure 
4. From figure 4 , for example, for $500(\mu \mathrm{g} / \mathrm{ml})$ concentration of about 1 micromoles equivalence of ascorbic acid was noticed in the lyophilized sample of the callus extracts.

\subsection{DPPH radical scavenging activity assay.}

Since DPPH assay is the most sensitive assay for determining the antioxidant property, the sample extracts with different concentrations were taken, and the assay performed. The standard DPPH assay always uses methanol or ethanol as a solvent. In this assay, Trolox equivalency is used as a standard value for determining the presence of antioxidants. Trolox equivalency is most often measured using the ABTS decolorization assay. The absorbance values were recorded at $517 \mathrm{~nm}$ with varying concentrations of the sample extracts. The scavenging activity was checked for various plant extracts compared with butyl hydroxyanisole (BHA) as a standard reported in the article [30].

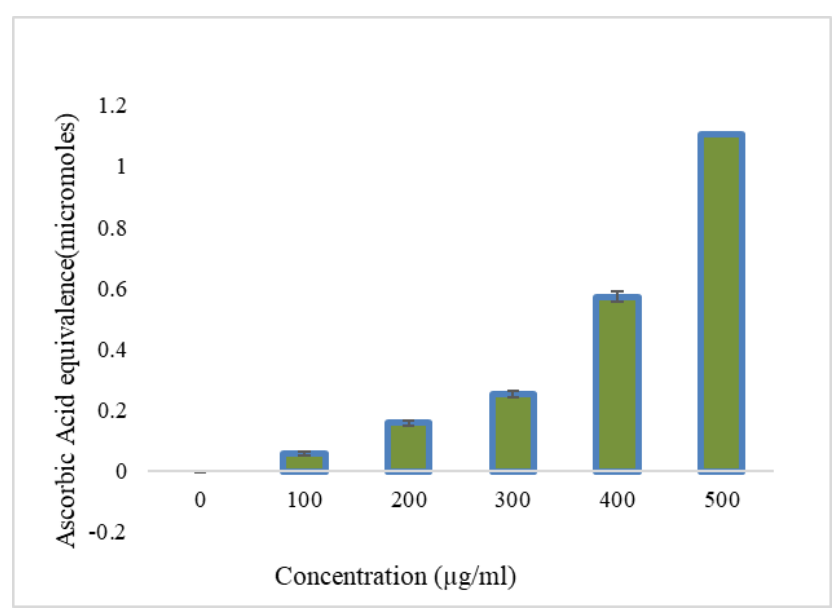

Figure 4. Total antioxidant capacity of total phenol from callus of A.indicum.

From figure 5, for example, $40(\mu \mathrm{g} / \mathrm{ml})$ concentration about 6 micromoles of Trolox equivalency was noticed. Thus the presence of antioxidant properties in the sample extracts was determined through DPPH assay.

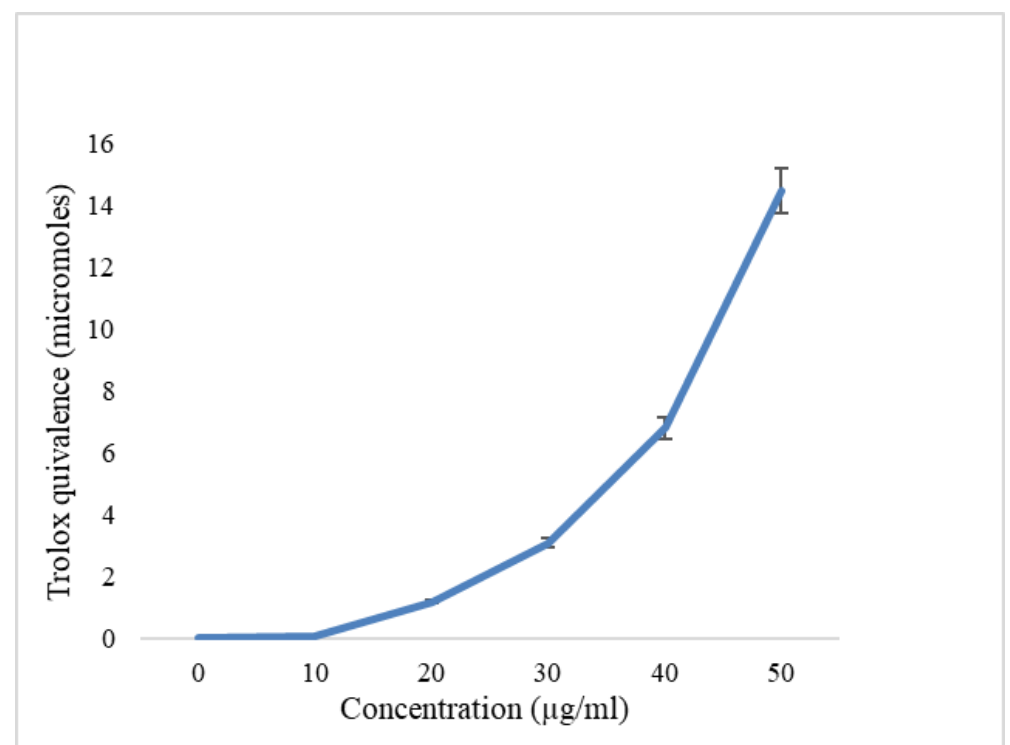

Figure 5. DPPH radical scavenging activity of total phenol from callus of A.indicum. 
Also, through DPPH assay, the presence of antioxidants was confirmed based on the IC50 principle. Also, the \% inhibition in DPPH assay for the chemical compounds were reported in the study made by [29] has shown for different concentrations of ethyl acetate, the $\%$ inhibition of the free radicals was found to be $81 \%$. Here the $\%$ inhibition was found to be $67 \%$. This means that the sample extracts of the callus can inhibit $67 \%$ of the free radicals, which are said to have antioxidant properties. From figure 6, the amount of DPPH radical decreased. On increasing the concentration, the percentage inhibition increased from 60.02 to 70 , following the IC50 principle. The data obtained revealed that extracts are free radical inhibitors and thus contain a potent antioxidant.

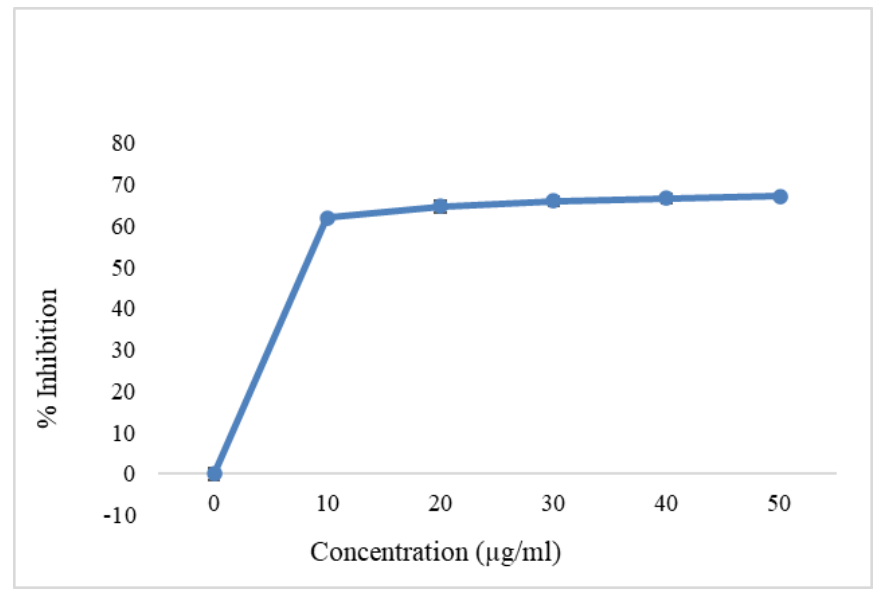

Figure 6. Percentage inhibition of the DPPH radicals due to antioxidant property.

\subsection{Reducing antioxidant power assay.}

Reducing antioxidant power assay is a widely used method for determining antioxidant molecules present in the sample where antioxidants are used as reductants in a redox-linked colorimetric reaction. The study revealed that the antioxidant property of various fruits peel, pulp, and seed fractions had been reported in the study made by [31]. The study reported here is the most comprehensive comparison of the antioxidant activity among different fruit fractions. Some fruit peel and seed fractions have strong antioxidant activity and may be rich sources of antioxidants. Similarly, here the sample extract concentration varies from 10 to 50 $(\mu \mathrm{g} / \mathrm{ml})$, the absorbance values are seemed to be increased.

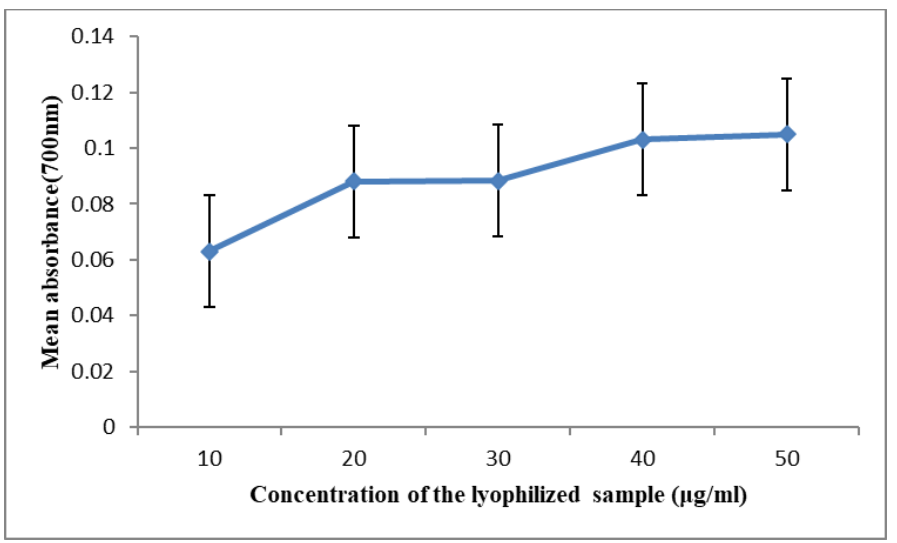

Figure 7. Reducing antioxidant power assay of total phenol from callus.

From Figure 7. the absorbance value increases with an increase in concentration. Thus, reducing antioxidant power assay shows that the antioxidant activity is present in the lyophilized extract of the callus biomass. 


\section{Conclusions}

Initially, the induction of callus formation depends on plant species and which tissues are available for explant culture. An exogenous supply of hormone is required, even using specific media like MS. After callus induction, the extraction and quantification of total phenol from the induced callus and leaves of Abutilon indicum phytochemical assays such as phenolic assay was done with the hot and cold leaf extracts, and the comparative studies were done. Ethanolic extracts of leaf-derived callus were then subjected to TLC, and PTLC was carried out. A fraction from PTLC and based on total phenolic content of callus extract, total antioxidant capacity, DPPH, assay, and reducing power assay performed. Finally, we concluded that, compared to leaf, callus shows a higher concentration of total phenol and shows promising antioxidant activity. So, it gives scope for further exploration and purification and application of total phenol from callus Abutilon indicum.

\section{Funding}

This research received no external funding.

\section{Acknowledgments}

The authors would like to thank the Kumaraguru College of Technology, Coimbatore, for providing research facilities and support to perform these experimental studies.

\section{Conflicts of Interest}

The authors declare no conflict of interest.

\section{References}

1. Rajeshwari, S.; Sevarkodiyone, S.P. Medicinal properties of Abutilon indicum. International Journal of Research In Phytochemical And Pharmacological Sciences 2018, 1, 1-4, https://doi.org/10.33974/ijrpps.v1i1.5.

2. Sasikala, R.P.; Sangeetha, K.; Meena, K.S. Comparative antibacteria 1 and antifungal activities of benzene extract of three medicinal plants. Innovare J Life Sci. 2017, 5, 3-5.

3. Khandel, P.; Yadaw, R.K.; Soni, D.K.; Kanwar, L.; Shahi, S.K. Biogenesis of metal nanoparticles and their pharmacological applications: present status and application prospects. Journal of Nanostructure in Chemistry 2018, 8, 217-254, https://doi.org/10.1007/s40097-018-0267-4.

4. Vallam, T. The effect on antimicrobial activity of Thespesia populnea and Abutilon indicum against clinical microbes. Res. j. life sci, 2019. DOI: 10.26479/2019.0503.11

5. Das, K,; Khan, M.S,; Namratha, N,; Swetha, R,; Gezici, S. Comparative phytochemical screening, elemental content and chromatographic evaluation for detection and quantification of polyphenolic compounds for strong antioxidant activity of various extracts of Abutilon indicum (Link) Sweet leaves. Ann. Phytomed. 2019, 8(1), 36-44. DOI: 10.21276/ap.2019.8.1.4.

6. Mahalik,G,; Jali, P,; Satapathy, K.B,; Sahoo, S. Review on Ethnomedicinal, Pharmacological and Phytochemical Constituents of Abutilon Indicum (L.) Sweet. Journal of the Gujarat Research Society 2019, 21, 334-40.

7. Thakor, P.; Mehta, J.B.; Patel, R.R.; Patel, D.D.; Subramanian, R.B.; Thakkar, V.R. Extraction and purification of phytol from Abutilon indicum: cytotoxic and apoptotic activity. RSC Advances 2016, 6, 48336-48345, https://doi.org/10.1039/C5RA24464A.

8. Shikhar Jain, R.; Sonwane, T.; Shaikh, A. Indian species and their medicinal property. Research Journal of Pharmacology and Pharmacodynamics 2020, 12, 142-4, https://doi.org/10.5958/2321-5836.2020.00026.9

9. Tian, C.; Zhang, P.; Yang, C.; Gao, X.; Wang, H.; Guo, Y.; Liu, M. Extraction process, component analysis, and in vitro antioxidant, antibacterial, and anti-inflammatory activities of total flavonoid extracts from Abutilon theophrasti medic. Leaves. Mediators Inflamm. 2018, 13, https://doi.org/10.1155/2018/3508506.

10. Yadav, R.K.; Verma, N. Medicinal uses of common weed plants from bareilly college, bareilly campus, Uttar pradesh, India. Plant Arch 2020. 
11. Surywanshi, V.S.; Umate, S.R. A Review on Phytochemical Constituents of Abutilon indicum (Link) Sweet - An Important Medicinal Plant in Ayurveda. Plantae Scientia 2020, 3, 15-19, https://doi.org/10.32439/ps.v3i3.15-19.

12. Ferdous, M.; Rahman, M.; Mahamud, K.; Ayshi, S.; Sohel, M. Pharmacologicals and Phytochemicals Potential of Abutilon indicum: A Comprehensive Review. American Journal of BioScience 2015, 3, 5-11, https://doi.org/10.11648/j.ajbio.s.2015030201.12.

13. Radha, P. Ethno-gynaecological knowledge on medicinal plants among the rural communities of Tiruppur district, Tamil Nadu, India. Medicinal Plants - International Journal of Phytomedicines and Related Industries 2021, 12, 656-65, http://dx.doi.org/10.5958/0975-6892.2020.00079.9.

14. Mei, B.C.; Lyga, J.W.U.S. Patent No. 9,757,327. Washington, DC: U.S. Patent and Trademark Office. 2017.

15. Azahar, N.F.; Gani, S.S.A.; Mohd Mokhtar, N.F. Optimization of phenolics and flavonoids extraction conditions of Curcuma Zedoaria leaves using response surface methodology. Chemistry Central Journal 2017, 11, 1-0, https://doi.org/10.1186/s13065-017-0324-y.

16. Jinal, N.H.; Amaresan, N. Evaluation of biocontrol Bacillus species on plant growth promotion and systemicinduced resistant potential against bacterial and fungal wilt-causing pathogens. Archives of Microbiology 2020, 202, 1785-1794, https://doi.org/10.1007/s00203-020-01891-2.

17. Musthafa, S.A.; Kasinathan, T.; Bhattacharyya, R.; Muthu, K.; Kumar, S.; Munuswamy-Ramanujam, G. Gallic acid synergistically enhances the apoptotic ability of Abutilon indicum Linn. Stem fraction inhuman U87 glioblastoma cells. Materials Today: Proceedings 2021, 40, S216-S223, https://doi.org/10.1016/j.matpr.2020.10.285.

18. Sajjalaguddam, R.R.; Paladugu, A. Phenylalanine enhances Quercetin content in In vitro cultures of Abutilon indicum L. J. Appl. Pharm. Sci. 2015, 5, 80-4, https://doi.org/10.7324/JAPS.2015.501014.

19. Krishnan, V.; Ahmad, S.; Mahmood, M. Antioxidant potential in different parts and callus of Gynura procumbens and different parts of Gynura bicolor. BioMed Res. Int. 2015, 30, https://doi.org/10.1155/2015/147909.

20. Ani, V.; Varadaraj, M.C.; Naidu, K.A. Antioxidant and antibacterial activities of polyphenolic compounds from bitter cumin (Cuminum nigrum L.). European Food Research and Technology 2006, 224, 109-115, https://doi.org/10.1007/s00217-006-0295-z

21. Amzad Hossain, M.; Shah, M.D. A study on the total phenols content and antioxidant activity of essential oil and different solvent extracts of endemic plant Merremia borneensis. Arabian Journal of Chemistry 2015, 8, 66-71, https://doi.org/10.1016/j.arabjc.2011.01.007.

22. Muthuselvi, S.; Sathishkumar, T.; Kumaresan, K.; Rajeshkumar, M. Improved inulinase activity by Penicillium purpurogenum grown in microwave pretreated coffee spent by L16 orthogonal design of experiment. Innov. Rom. Food Biotechnol. 2012, 1, 44-50.

23. Rajendran, R.; Narashimman, B.S.; Trivedi, V.; Chaturvedi, R. Isolation and quantification of antimalarial $\mathrm{N}$-alkylamides from flower-head derived in vitro callus cultures of Spilanthes paniculata. Journal of Bioscience and Bioengineering 2017, 124, 99-107, https://doi.org/10.1016/j.jbiosc.2017.02.001

24. Singariya, P.; Kumar, P.; Mourya, K.K. Identification of steroid compound using preparative Thin Layer Chromatography, GC-MS and antimicrobial and antioxidant properties of Cenchrus setigerus (Poaceae). Int. J. of Pharm. \& Life Sci. (IJPLS) 0976-7126 2012, 3, 1909-1916.

25. Serpen, A.; Gökmen, V.; Pellegrini, N.; Fogliano, V. Direct measurement of the total antioxidant capacity of cereal products. Journal of Cereal Science 2008, 48, 816-820, http://dx.doi.org/10.1016/j.jcs.2008.06.002.

26. Garcia, E.J.; Oldoni, T.L.; Alencar, S.M.; Reis, A.; Loguercio, A.D.; Grande, R.H. Antioxidant activity by DPPH assay of potential solutions to be applied on bleached teeth. Braz. Dent. J. 2012, 23, 22-7, https://doi.org/10.1590/s0103-64402012000100004.

27. Berker, K.I.; Güçlü, K.; Tor, İ.; Apak, R. Comparative evaluation of Fe(III) reducing power-based antioxidant capacity assays in the presence of phenanthroline, batho-phenanthroline, tripyridyltriazine (FRAP), and ferricyanide reagents. Talanta 2007, 72, 1157-1165, https://doi.org/10.1016/j.talanta.2007.01.019.

28. Ningsih, D.S.; Idroes,R.; Bachtiar, B.M. The potential of five therapeutic medicinal herbs for dental treatment: A review. IOP Conference Series: Materials Science and Engineering. IOP Publishing 2019, 523, https://doi.org/10.1088/1757-899X/523/1/012009.

29. Riaz, T.; Abbasi, A.M.; Shahzadi, T.; Ajaib, M.; Khan, M.K. Phytochemical screening, free radical scavenging, antioxidant activity and phenolic content of Dodonaea viscosa. J. Serb Chem. Soc. 2012, 77, 423-35, https://doi.org/10.2298/JSC110621183R.

30. David, J.P.; Meira, M.; David, J.M.; Brandão, H.N.; Branco, A.; de Fátima Agra, M.; Barbosa, M.R.V.; de Queiroz, L.P.; Giulietti, A.M. Radical scavenging, antioxidant and cytotoxic activity of Brazilian Caatinga plants. Fitoterapia 2007, 78, 215-218, https://doi.org/10.1016/j.fitote.2006.11.015.

31. Guo, C.; Yang, J.; Wei, J.; Li, Y.; Xu, J.; Jiang, Y. Antioxidant activities of peel, pulp and seed fractions of common fruits as determined by FRAP assay. Nutrition Research 2003, 23, 1719-1726, https://doi.org/10.1016/j.nutres.2003.08.005. 